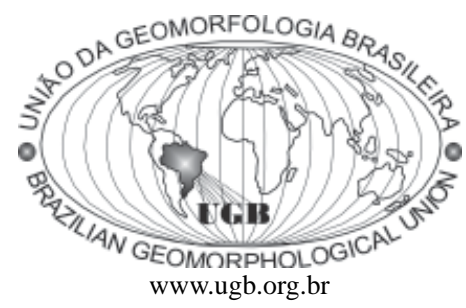

\title{
ANÁLISE E COMPARTIMENTAÇÃO MORFOMÉTRICA DA BACIA HIDROGRÁFICA DO ALTO RIO DAS VELHAS - REGIÃO CENTRAL DE MINAS GERAIS
}

\author{
Luis Felipe Soares Cherem \\ Programa de Pós-graduação em Evolução Crustal e Recursos Naturais - UFOP - Escola de Minas/Campus do Morro do \\ Cruzeiro/UFOP, Bauxita, Ouro Preto, MG - CEP: 35400-000-e-mail: luis.cherem@gmail.com \\ Antônio Pereira Magalhães Jr. \\ Departamento de Geografia - UFMG - Instituto de Geociências/Campus Pampulha/UFMG, Av. Antônio Carlos, 6.627, \\ Pampulha, Belo Horizonte, MG - CEP: 31270-901 - e-mal: magalhaesufmg@yahoo.com.br \\ Sérgio Donizete Faria \\ Departamento de Cartografia - UFMG - Instituto de Geociências/Campus Pampulha/UFMG, Av. Antônio Carlos, 6.627, \\ Pampulha, Belo Horizonte, MG - CEP: 31270-901 - e-mail: fariamaracai@yahoo.com.br
}

\begin{abstract}
Resumo
A bacia hidrográfica do Rio das Velhas, porção central de Minas Gerais, é objeto de estudos geomorfológicos desde o ínicio do século XX e, durante esse período, avanços conceituais e metodológicos permitiram que os resultados obtidos inicialmente fossem reinterpretados num novo contexto científico. Os estudos desenvolvidos nessa bacia se concentram em seu alto curso por este corresponder ao núcleo da Província Mineral do Quadrilátero Ferrífero, uma paisagem montanhosa peculiar marcada por forte condicionamento litológico, estrutural e tectônico. Entretanto, o foco de análise da geomorfologia regional ainda não havia se voltado à análise morfométrica dessa bacia hidrográfica. Essa análise permite a compartimentação de bacias hidrográficas em agrupamentos de sub-bacias com características homogêneas e, consequentemente, subsidia estudos geomorfológicos de outra natureza e o planejamento e a gestão ambiental do território. Nesse contexto, esse artigo visa fornecer esse tipo de subsídio para a bacia hidrográfica do alto Rio das Velhas. Para tanto, são apresentadas a análise e a compartimentação morfométricas dessa bacia, avaliando a significância estatística das Leis de Horton e a distribuição espacial dos demais parâmetros morfométricos. Os resultados indicam o agrupamento de sub-bacias para nove dos onze parâmetros morfométricos avaliados. Esse comportamento permite a compartimentação dessa bacia em cinco grupos, cuja diferenciação se deve a aspectos lito-estruturais e tectônicos. Observa-se que os aspectos litológicos condicionam a composição desses agrupamentos, sendo os principais elementos na configuração do relevo e da rede de drenagem, embora haja variação morfométrica entre as porções E e W no granito-gnaisse do Complexo do Bação.
\end{abstract}

Palavras-chave: Província Mineral do Quadrilátero Ferrífero, relevo montanhoso, análise espacial.

\begin{abstract}
The Das Velhas River Basin, in central Minas Gerais state, Southeastern Brazil, has been studied since the beginning of the $20^{\text {th }}$ century. Along this last century the conceptual and technical progress has allowed the reinterpretation of previous results under new aegis. Geoscientific studies developed for this river basin have focused its upper basin because of its correspondence to the core area of the Mineral Province of Quadrilátero Ferrífero, a peculiar mountainous landscape, marked by strong litho-structural and tectonic forcing. However, none morphometric analysis has been done for this river basin, in spite of the
\end{abstract}


several regional geomorphological studies. This sort of spatial analysis allows defining major compartments compounded of sub-basins with similar features, which are essential for environmental planning and management of the territory and also for future geomorphologic studies. In this context, this paper aims providing such support for the Upper Rio das Velhas basin. For this, we have done the morphometric analysis and partitioning of this river basin, taking into account the Horton's Law of drainage basin composition and other morphometric parameters. The results show the grouping of sub-basins for nine (9) of the eleven (11) morphometric parameters taken in count. This behavior allows us to partitioning the upper Rio das Velhas basin into five (5) major partitions, where structure plays a main role, followed by lithology and tectonics. Nevertheless, this control is quite moderate for the granitic area, where local base level control is predominant on dividing it into the eastern/ western portions.

Keywords: Mineral Province of Quadrilátero Ferrífero, mountainous relief, spatial analysis.

\section{Introdução}

A concepção sistêmica de meio ambiente tem sido utilizada pela Geomorfologia na literatura nacional e internacional desde a segunda metade do século XX. Nesse contexto, a realidade é representada por meio de modelos, nos quais o objeto de estudo é entendido como um sistema e as partes desse sistema como elementos e fluxos de energia e matéria. Na concepção sistêmica, o tipo de análise varia de acordo com os objetos e objetivos definidos em cada pesquisa (Christofoletti, 1999). Um dos tipos de análise possível é a análise morfométrica, a qual tem como objetivo geral o entendimento do arranjo e distribuição de determinados elementos na paisagem, sendo utilizados índices (parâmetros) que correlacionem esses elementos a partir da mensuração de seus atributos.

Uma das unidades espaciais adotada em análises morfométricas é a bacia hidrográfica por facilitar o estudo das relações de causas e efeitos entre trechos de montante e jusante, em termos de processos e formas geomorfológicas. A evolução da rede de drenagem determina a dinâmica das encostas e, portanto, a configuração das bacias. Neste sentido, o estudo morfométrico da rede de drenagem envolve, direta ou indiretamente, o estudo dos sistemas de encostas, e sinaliza os processos envolvidos na configuração espacial das bacias hidrográficas (Schumm, 1956).

Os processos e formas estudados nas análises morfométricas são representados por meio de parâmetros que relacionam diversos atributos de uma bacia hidrográfica, abordagem esta proposta inicialmente por Horton (1945) na definição pioneira das leis de composição de bacias hidrográficas. Posteriormente, novos parâmetros foram desenvolvidos por outros pesquisadores, possibilitando interpretações mais completas (Strahler, 1952; Schumm, 1956; Sauchyn et al., 1998; Scheidegger 2001; Ruszikiczay-Rudiger, 2007; Walcott \& Summerfield, 2007). Esses parâmetros permitem a análise comparativa de sub-bacias hidrográficas, possibilitando o entendimento da variação e do arranjo espacial da rede de drenagem e das vertentes. No contexto exposto, esse trabalho tem como objetivo a análise e a compartimentação morfométricas da bacia do alto Rio das Velhas, localizada na região central de Minas Gerais (Figura 1A).

\section{Área de Estudo}

O Rio das Velhas é o afluente da margem direita do Rio São Francisco que drena as águas da porção central do Estado de Minas Gerais (Figura 1A). Seu alto curso localiza-se no interior da Província Mineral do Quadrilátero Ferrífero, cujos interflúvios são os complexos serranos sustentados pelas formações ferríferas bandadas (BIF - banded iron formations): Serras da Moeda de Itabirito, a oeste; Serras do Curral e da Piedade, a norte; Serras da Água Limpa e da Gandarela, a leste; e Serra do Ouro Branco, a sul.

O condicionamento lito-estrutural sobre o relevo da bacia do alto Rio das Velhas não é observado apenas nos interflúvios, mas sim em toda sua extensão (Figura 1B e C), conforme ressalta Barbosa (1980). As porções mais elevadas, correspondendo a cristas escarpadas com altitude superior a $1.200 \mathrm{~m}$, coincidem com as bordas das sinclinais e são compostas por quartzitos e itabiritos do Supergrupo Minas, litotipos mais resistentes do Quadrilátero. Esses litotipos são responsáveis pela sustentação das elevações entre 1.200 e $1.000 \mathrm{~m}$, localizadas no interior dos sinclinais e compostas por rochas mais friáveis (preponderantemente, xistos, filitos e dolomitos). As porções mais rebaixadas da bacia têm altitudes inferiores a $800 \mathrm{~m}$ e correspondem, majoritariamente, às colinas formadas sobre rochas cristalinas arqueanas do Complexo do Bação.

Segundo Alkimin \& Marshak (1998), a estratigrafia da região é composta por gnaisses e migmatitos arqueanos (Complexo do Bação); sequência arqueana tipo greenstone belt do Supergrupo Rio das Velhas; e metassedimentos proterozóicos do Supergrupo Minas. Essas fácies foram deformadas pela intrusão dômica de rochas arqueanas em seu interior e por uma série de sinclinais/ anticlinais com eixos principais N/S e E/W e falhas de empurrão com vergência W (Figura 1C). 


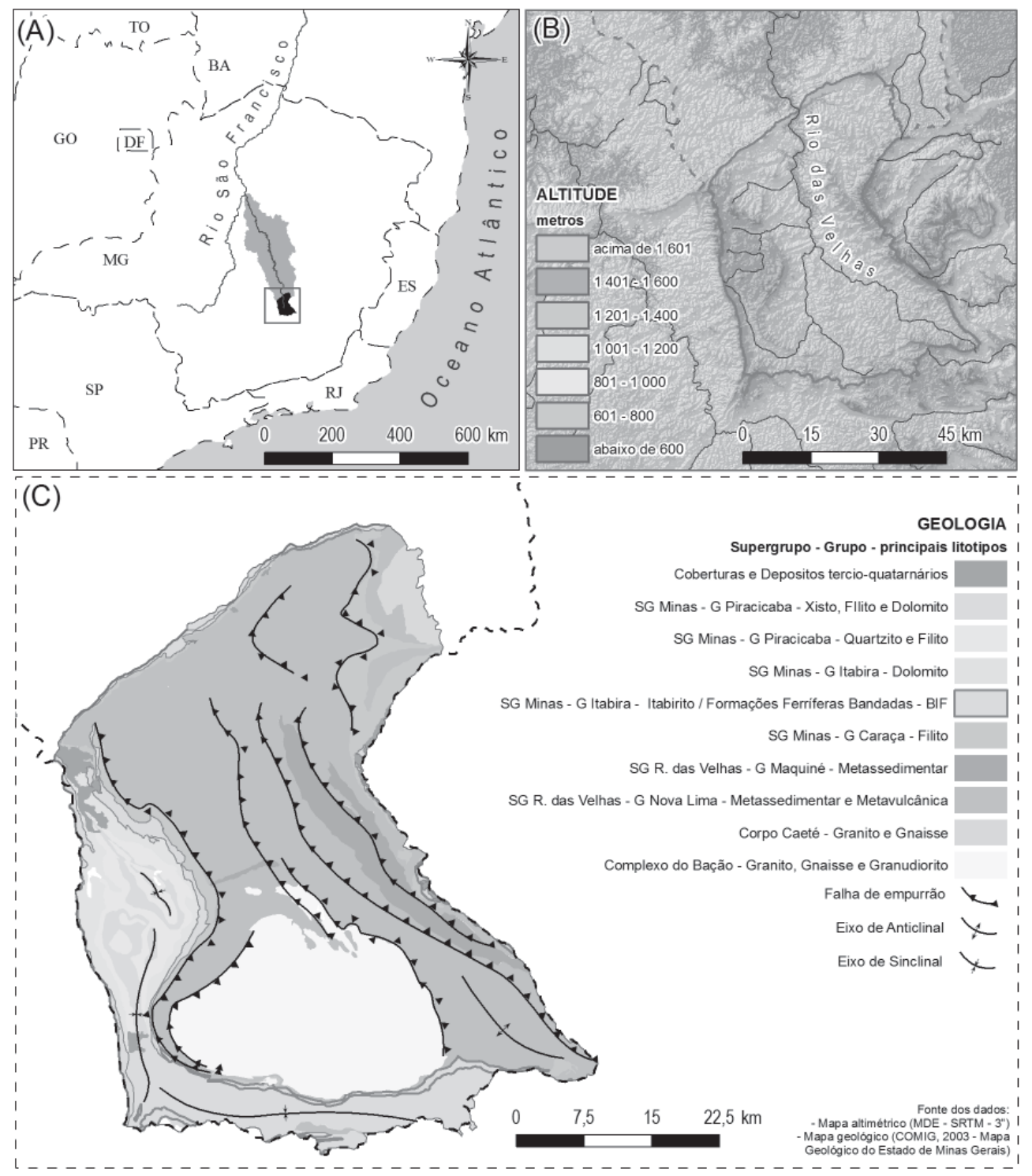

Figura 1 - (A) Localização da bacia do Rio das Velhas (em cinza) e de seu alto curso (em preto); (B) configuração do relevo e altimetria regional, e (C) da lito-estrutura da bacia do alto Rio das Velhas.

Assim, observa-se que a bacia do alto Rio das Velhas é composta por três patamares de resistência frente aos processos denudacionais: as terras altas, moldadas sobre substrato quartzítico e itabiritos; as terras médias com substrato de xisto e filitos; e as terras baixas, sobre granito e gnaisses. Em todos esses patamares predominam solos autóctones imaturos (Varajão et al., 2009), nas serras desenvolvem-se neossolos litólicos; nas altitudes médias e baixas, desenvolvem-se, principalmente, cambissolos (Figura 1B e C). Já nas áreas mais baixas a ocorrência de solos latossolos alóctones é marcante (Figueiredo et al., 2004).

\section{Metodologia}

Preparação dos dados topográficos e geração da base de dados composta pelos parâmetros morfométricos

Nessa etapa são utilizados os dados de altimetria e da rede de drenagem, digitalizados e corrigidos topologicamente, de sete folhas da Carta Topográfica do Brasil - 1:50.000 - IBGE, nas quais a bacia do alto Rio das Velhas está representada. A partir desses dados, a rede de drenagem foi hierarquizada de acordo com a proposta de Strahler (1952). As sub-bacias de todas as ordens (desde a primeira ordem até a mais elevada) foram delimitadas, tendo sido extraídos os seguintes atributos do relevo e da rede de drenagem, para as sub-bacias de todas as ordens: área da bacia, perímetro 
da bacia, comprimento da bacia, comprimento dos canais fluviais, comprimento vetorial dos canais fluviais, número de canais fluviais, declividade da bacia (mínima, média, máxima), declividade dos canais, altimetria (média, máxima e mínima) e variação altimétrica dos canais e das bacias.

Em seguida, foram calculados os seguintes parâmetros morfométricos, para todas as sub-bacias de quinta ordem: relação de bifurcação $(R b)$, relação de comprimento médio de canais $(R l)$, relação de gradiente de canais $(R g)$, relação de área de bacias $(R a)$, índice de sinuosidade (Is), índice de rugosidade (Ir), índice de circularidade de bacia (IC), declividade de canais $\left(D v_{\text {canal }}\right)$, declividade máxima e média de bacias $\left(D v_{\text {bacia }}\right)$, densidade de drenagem $(D d)$, densidade hidrográfica $(\mathrm{Dh})$, coeficiente de manutenção $(\mathrm{Cm})$, magnitude fluvial $(M f)$ e hierarquia fluvial $(H)$. Esses parâmetros são os mais frequentemente utilizados em análises morfométricas de bacias hidrográficas (Vestana et al. 2006, Feltran Filho \& Lima 2007, Santos \& Sobreira 2008).

Os parâmetros referentes às leis de Horton $(R b, R l, R g$ e $R a$ ) estão relacionados a normalidade da relação dos canais de determinada ordem com os canais de ordem imediatamente superior e inferior, gerando uma reta para o logaritmo dos valores de cada parâmetro em cada bacia. Essas retas tendem a ser curvilíneas quando a composição da rede de drenagem é perturbada por algum fenômeno ou feição geológicogeomorfológica (Vestana et al., 2006). A avaliação é feita a partir do cálculo da significância estatística $\left(\mathrm{R}^{2}\right)$ da equação da reta de regressão gerada para cada parâmetro, onde valores elevados $\left(R^{2}>0,95\right)$ indicam normalidade e valores inferiores a 0,95 indicam anormalidade. Os demais parâmetros são avaliados diretamente.

\section{Análise e compartimentação morfométrica da bacia do alto Rio das Velhas}

Nessa etapa foi realizada a análise morfométrica da bacia como um todo, visando o entendimento da morfometria dessa unidade. Os parâmetros gerados para todas as ordens hierárquicas foram considerados. Em seguida, foram definidas as sub-bacias de quinta ordem como a escala mais adequada para a compartimentação dessa bacia hidrográfica. Essa definição está baseada em duas características das sub-bacias: a relação entre número de bacias e área total ocupada. As sub-bacias de sexta ordem, apesar de terem área expressiva em relação à área total da bacia, são apenas quatro; e as sub-bacias de quarta ordem, apesar de numerosas (setenta e quatro), têm área pouco expressiva em relação ao total da bacia.

Em contrapartida, tem-se dezenove sub-bacias de quinta que correspondem a $3 / 4$ da área total da bacia. As dezenove sub-bacias são classificadas em quatro intervalos definidos segundo a distribuição de Jenks (1967), também conhecida por quebra natural. Optou-se por esse método por ele formar classes com reduzida variância, o que permite maior homogeneidade nos valores de uma mesma classe e também maior representatividade das médias de cada classe. Para os quatro parâmetros referentes à lei de composição de bacias hidrográficas de Horton, a classificação foi feita de acordo com a significância estatística dos valores $\left(\mathrm{R}^{2}\right)$ em cada bacia, a saber: maior que $99 \%$, entre 95 e $99 \%$, entre 80 e $95 \%$ e inferiores a $80 \%$.

Os parâmetros classificados foram representados em mapas temáticos, nos quais foi analisado o arranjo espacial das bacias (relação de vizinhança), ou grupos formados por bacias homogêneas (em mesma classe temática), ou grupos heterogêneos (bacias em classes diferentes). Após realizada essa análise para todos os parâmetros, a bacia do alto Rio das Velhas foi compartimentada em três tipos de agrupamentos, classificados segundo a estrutura espacial: forte, quando as bacias integrantes pertencem à mesma classe estatística (agrupamentos homogêneos); fracos, quando algumas bacias integrantes estão em classes estatísticas diferentes (agrupamentos pouco homogêneos); e aleatórios, quando as bacias de um agrupamento estão em classes estatísticas diferentes (agrupamentos heterogêneos).

\section{Resultados e Discussão}

\section{Análise morfométrica da bacia do alto Rio das Velhas}

A bacia do alto Rio das Velhas, na Carta Topográfica do Brasil - 1:50.000, é uma bacia de sétima ordem, composta por 4 canais de sexta ordem, 19 canais de quinta ordem, 75 canais de quarta ordem, 333 canais de terceira ordem, 1491 canais de segunda ordem e 6.014 canais de primeira ordem. $\mathrm{O}$ ordenamento desses canais permite o mapeamento das sub-bacias e a extração de atributos da rede de drenagem e do relevo. A elevada ordem hierárquica dessa bacia impede a derivação de alguns atributos dos canais e bacias de baixa ordem. Pelo mesmo motivo, as sub-bacias de segunda e primeira ordem não são delimitadas e a declividade média e sinuosidade dos canais de primeira, segunda e terceira ordens não são calculadas.

A bacia do alto Rio das Velhas tem magnitude fluvial $(M f)$ igual a 6.014 cabeceiras de drenagem. Os canais de quarta e quinta ordens são em geral canais retilíneos a sinuosos, tendo $I s$ iguais a 1,2 e 1,3, respectivamente. Os canais de sexta ordem e o canal principal (sétima ordem) são sinuosos a meandrantes, tendo $I s$ iguais a 1,5 e 1,6 respectivamente. A bacia é circunforme, tendo $I c$ igual a 0,48 , o que indica reduzido tempo de concentração das águas e elevado potencial de cheias. Os valores baixos de $D d$ e $D h$ indicam reduzida capacidade de gerar novos canais e média capacidade de infiltração. 
O índice de rugosidade $\left(I r_{t}\right)$ alto, igual a 462 , é decorrente da elevada amplitude altimétrica da bacia ( $\Delta$ alt $t_{1}=$ 1.050 m). Essa amplitude, por sua vez, é consequência da inclusão das escarpas serranas que delimitam a bacia, as quais influenciam a amplitude altimétrica sem terem representatividade espacial nessa bacia. Caso essas áreas sejam desconsideradas $(\Delta a l t=750 \mathrm{~m})$, o índice de rugosidade da bacia $\left(I r_{2}\right)$ assume o valor de 304, conforme apresentado na Tabela 1.

Tabela 1 - Parâmetros morfométricos calculados para a bacia do alto Rio das Velhas.

\begin{tabular}{cccccccccccc}
\hline Parâmetro & $\boldsymbol{H}$ & $\boldsymbol{M} \boldsymbol{f}$ & $\boldsymbol{I} \boldsymbol{s}$ & $\boldsymbol{I c}$ & $\boldsymbol{D} \boldsymbol{D}$ & $\boldsymbol{D d}$ & $\boldsymbol{C m}$ & $\boldsymbol{I r}_{\boldsymbol{I}}$ & $\boldsymbol{I r}_{2}$ & $\boldsymbol{\Delta a l t}_{\boldsymbol{1}}$ & $\boldsymbol{\Delta a l t}_{2}$ \\
\hline Valor & $7^{\mathrm{a}}$ & 6.014 & 1,54 & 0,48 & 3,52 & 2,48 & 402 & 462 & $304^{*}$ & 1.050 & $750^{*}$ \\
Unidade & - & - & - & - & $\mathrm{rio} / \mathrm{km}^{2}$ & $\mathrm{~km} / \mathrm{km}^{2}$ & $\mathrm{~m}^{2}$ & - & - & $\mathrm{m}$ & $\mathrm{m}$ \\
\hline
\end{tabular}

*Valor desconsidera escarpas por essas não terem representatividade espacial na variação altimétrica do relevo da bacia.

Os índices que representam as leis de composição da rede de drenagem de Horton ( $R l, R a, R b$ e $R g$ ), calculados para a bacia do alto Rio das Velhas, apresentaram resultados estatisticamente significativos (considerando significância de 95\%), demonstrando que essa bacia, na escala de análise adotada, apresenta comportamento próximo ao modelo proposto pelo autor em 1945. Os valores desses parâmetros tendem a formar uma reta entre as ordens sucessivas, conforme apresentado na Figura 2. Entretanto, são observadas anomalias no $R g$ dos canais de terceira ordem e no $R l$ dos canais de primeira ordem (Figura 2).

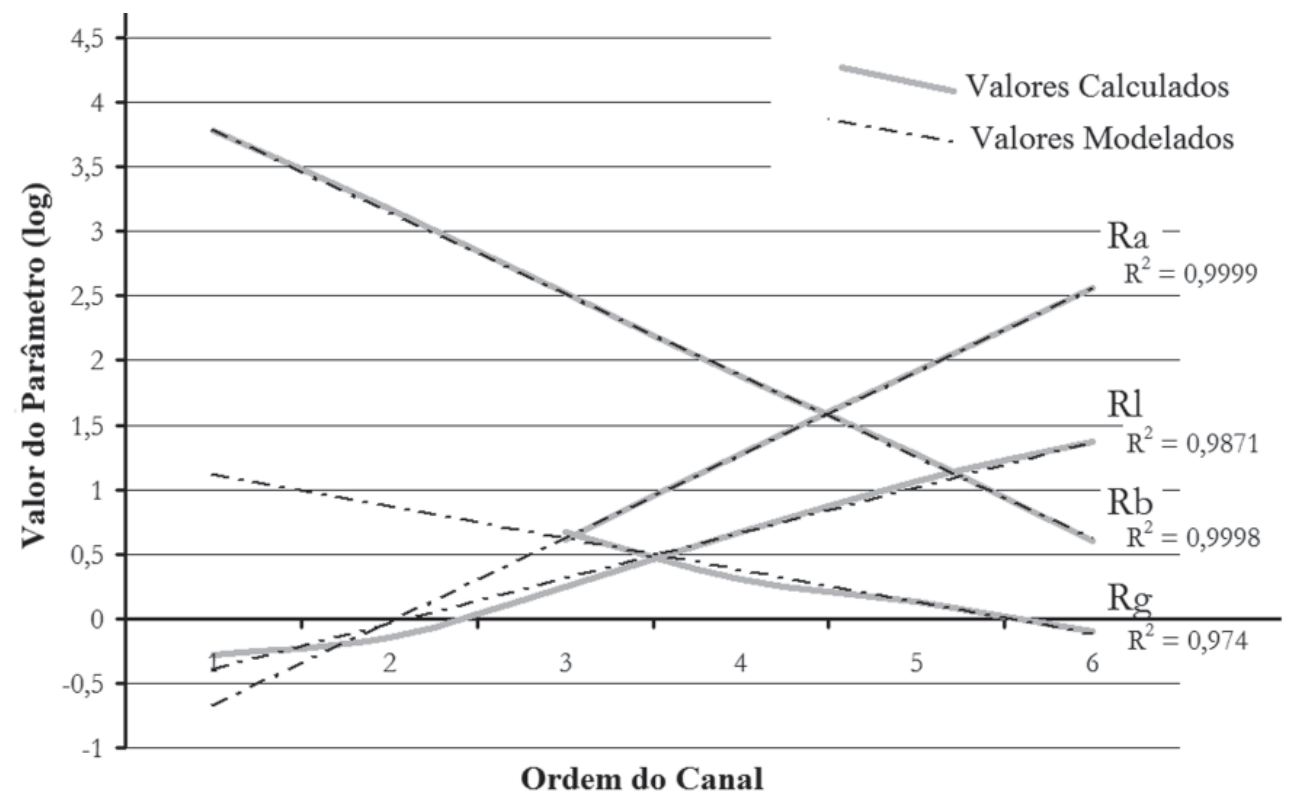

Figura 2 - Retas de regressão linear do logaritmo dos parâmetros de Horton para a bacia do alto Rio das Velhas, com destaque para as duas anomalias observadas (destaques circulares) para a relação de comprimento (Rl) e de gradiente de canais (Rg).

A relação média do gradiente de canais $(R g)$ esperada para os canais de quarta ordem (representada na reta da regressão gerada para a relação de gradiente de canais na Figura 2) é inferior ao calculado, o que significa que esses canais têm declividade média inferior ao valor esperado pelo modelo de Horton (1945). Essa anomalia no gradiente de canais pode ser justificada pelo forte controle estrutural da região que possibilita a formação de canais meandrantes em áreas mais elevadas com maior energia potencial para erosão (Santos et al., 2009). 
$\mathrm{O}$ valor de $R l$ calculado para os canais de primeira ordem é superior ao esperado pelo modelo e para os canais de segunda ordem é inferior. Isso ocorre pelo fato do comprimento médio dos canais de primeira ordem $(0,52 \mathrm{~km})$ ser bem próximo do valor do comprimento médio dos canais de segunda ordem $(0,72 \mathrm{~km})$. Essa anomalia se justifica pelo controle estrutural sobre a drenagem: os canais de primeira ordem que drenam sobre as escarpas dos sinclinais com relevo invertido esculpidos nas rochas metassedimentares do Supergrupo Minas (Barbosa \& Rodrigues, 1967) são canais extensos, bem como os canais que drenam sobre o embasamento granito-gnáissico (Complexo do Bação). das Velhas

Compartimentação morfométrica da bacia do alto Rio

Os 14 parâmetros calculados para as 19 sub-bacias de quinta ordem apresentaram valores com padrão de distribuição espacial e estatística variado, conforme pode ser observado na Tabela 2. Os parâmetros $R b$ e $R a$ apresentaram elevada significância estatística $\left(\mathrm{R}^{2}>0,98\right)$ e estrutura espacial dominada por agrupamentos fracos; $\mathrm{o} R l$ apresenta estrutura espacial dominada por agrupamentos fortes, embora tenha baixa significância estatística $\left(\mathrm{R}^{2}=0,80\right)$. O parâmetro $R g$ tem agrupamentos dominados por agrupamentos fracos com a menor significância estatística $\left(\mathrm{R}^{2}=0,73\right)$, conforme ilustrado na Figura 3.

Tabela 2 - Classificação da estrutura espacial dominante quanto aos parâmetros em sub-bacias de quinta ordem.

\begin{tabular}{|c|c|c|c|c|}
\hline Parâmetros & $\begin{array}{c}\text { Estrutura Espacial } \\
\text { Dominante }\end{array}$ & $\begin{array}{c}\text { Média } \\
\text { (M) }\end{array}$ & $\begin{array}{l}\text { Desvio Padrão } \\
\text { (DP) }\end{array}$ & $\begin{array}{c}\text { Significância } \\
\text { Estatística }\left(R^{2}>0,95\right)\end{array}$ \\
\hline$R b$ & Agrupamentos Fracos & 0,987 & 0,013 & $\operatorname{Sim}$ \\
\hline$R l$ & Agrupamentos Fortes & 0,804 & 0,296 & Não \\
\hline$R g$ & Agrupamentos Aleatórios & 0,736 & 0,343 & Não \\
\hline$R a$ & Agrupamentos Fracos & 0,982 & 0,021 & Sim \\
\hline$I r$ & Agrupamentos Fortes & - & - & - \\
\hline$I c$ & Agrupamentos Fracos & - & - & - \\
\hline$D d$ & Agrupamentos Fortes & - & - & - \\
\hline$D h$ & Agrupamentos Fortes & - & - & - \\
\hline $\mathrm{Cm}$ & Agrupamentos Fortes & - & - & - \\
\hline$M f$ & Agrupamentos Fortes & - & - & - \\
\hline$D v_{\text {hacia }}$ & Agrupamentos Fortes & - & - & - \\
\hline
\end{tabular}

OBS: Dv canal e Is: parâmetros sem potencial para avaliação de estrutura espacial, por terem sido medidos para elementos lineares.

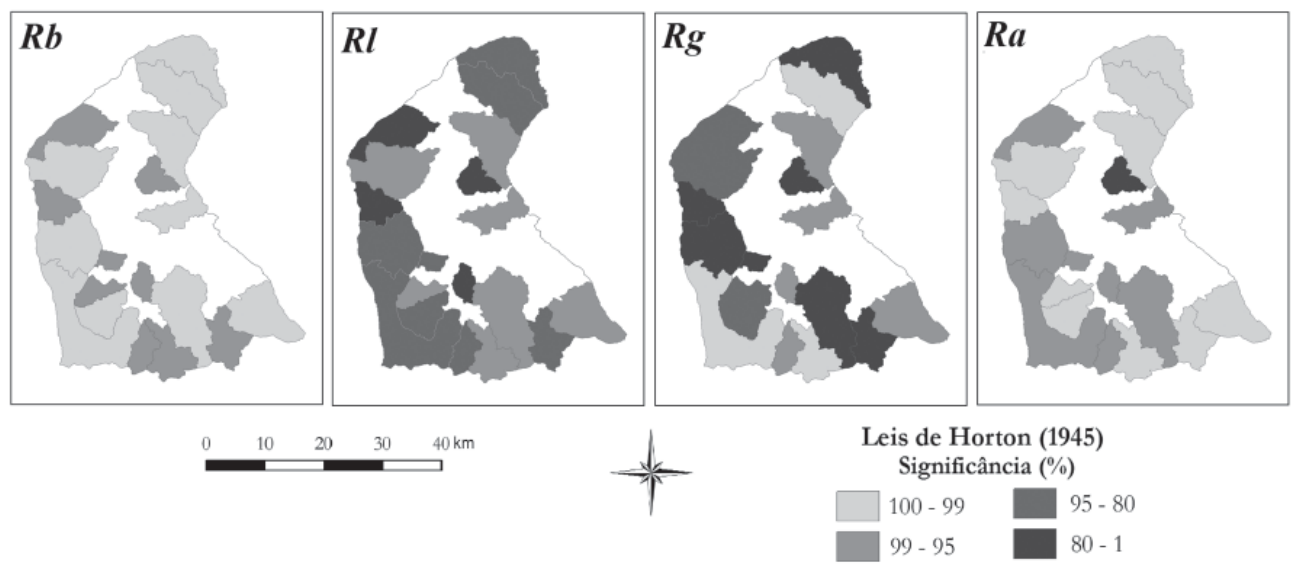

Figura 3 - Representação espacial da significância estatística $\left(R^{2}\right)$ dos parâmetros referentes às leis de Horton (1945) para as sub-bacias de quinta ordem da bacia do alto Rio das Velhas.

Os demais parâmetros, excluído o $I c$, apresentam estrutura espacial com agrupamentos fortes, embora a declividade média da bacia $\left(D v_{\text {bacia }}\right)$ dê origem a agrupamentos pouco estruturados (agrupamentos fracos), conforme apresentado na Figura 4. A densidade hidrográfica $(D h)$ apresenta valores mais próximos à média para a porção nordeste e sudoeste, e valores baixos para as porções noroeste e sudeste. Esse comportamento é também observado para a densidade de 
drenagem $(D d)$, embora os valores observados para a porção sudeste sejam mais elevados e homogêneos. Destaca-se que para todos os parâmetros calculados, o agrupamento mais estruturado é o que corresponde à porção sudoeste da bacia do alto Rio das Velhas, conforme pode ser observado nas Figuras 3 e 4.
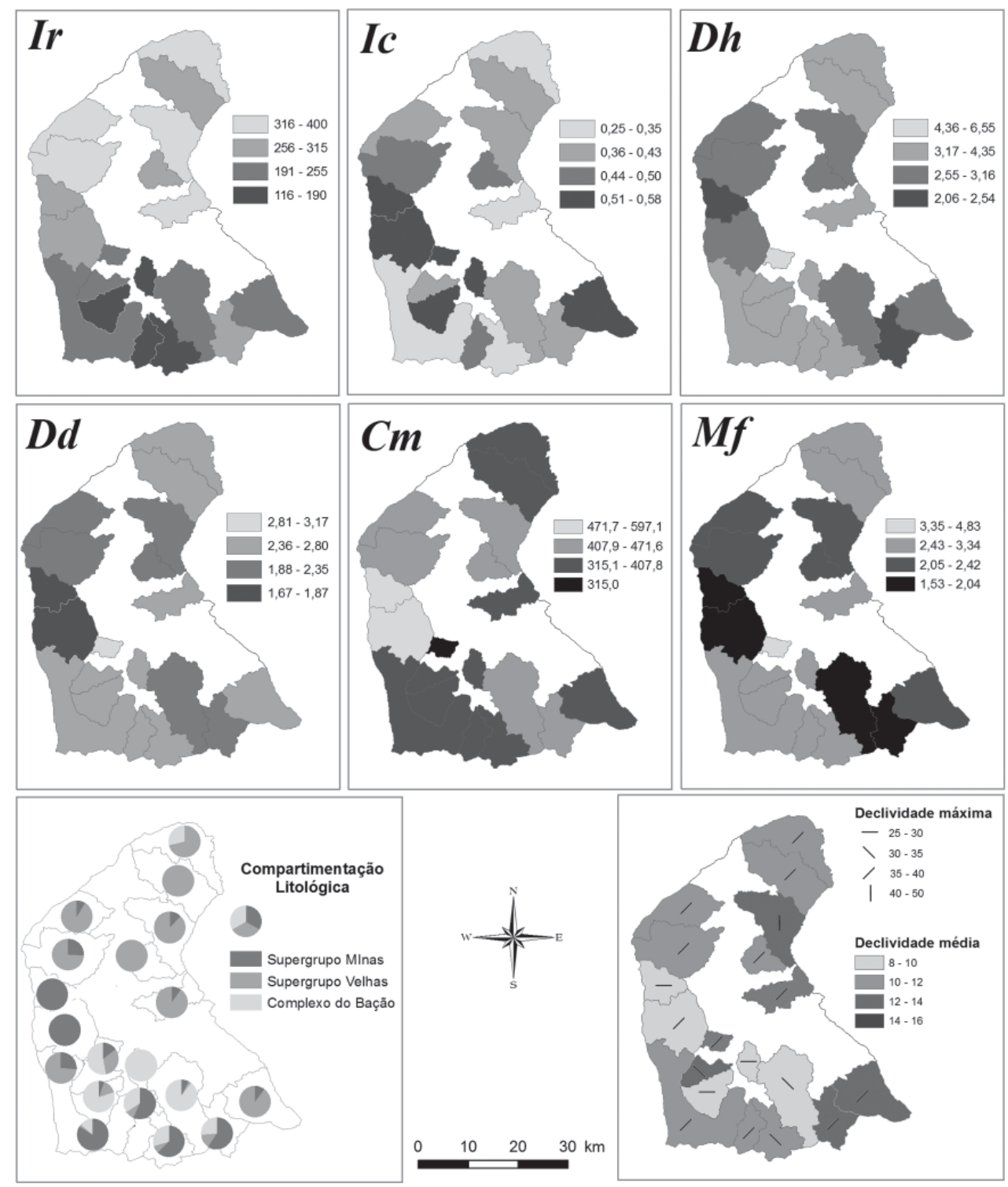

Figura 4 - Distribuição espacial dos agrupamentos dos parâmetros morfométricos, definidos por quebra natural, para as sub-bacias de quinta ordem da bacia do alto Rio das Velhas.

O coeficiente de manutenção $(\mathrm{Cm})$ e a magnitude fluvial $(M f)$ apresentam estrutura espacial semelhante a da densidade de drenagem $(D d)$, por serem parâmetros derivados diretamente desse último. Esses parâmetros indicam, respectivamente, a área necessária para geração de um canal de primeira ordem e a quantidade de cabeceiras de drenagem. A estrutura dos valores calculados demonstra a influência lito-estrutural, dado que: (i) as sub-bacias que drenam o Sinclinal da Moeda (borda oeste do Quadrilátero) apresentam as menores densidades de cabeceiras de drenagem; (ii) as sub-bacias que apresentam majoritariamente substrato nas rochas do Supergrupo Velhas apresentam 
valores médios para esses parâmetros, como é o caso das sub-bacias da porção norte.

O índice de rugosidade (Ir) apresenta dois agrupamentos principais: sub-bacias de norte e sub-bacias de sul. Essa estrutura demonstra que a rugosidade do relevo é maior para as sub-bacias afluentes da porção mais a jusante da bacia em estudo e menor para as sub-bacias de montante. Essa estrutura vai ao encontro daquela observada para os dados de declividade média e máxima, uma vez que as sub-bacias da porção norte apresentam valores elevados para as declividades média e máxima, conforme ilustrado na Figura 4. A correlação entre $I r$ e a declividade não é observada para a porção sudoeste da bacia. Essa porção corresponde ao trecho onde há a maior heterogeneidade litológica dentro da bacia do alto Rio das Velhas, conforme ilustrado na Figura 4. Deste modo, observa-se que, em geral, as sub-bacias litologicamente mais heterogêneas apresentam valores mais baixos de $I r$. O comportamento de $I r$ corresponde ao princípio que as bacias apresentam uma evolução marcada pela dissecação no sentido remontante.

As declividades média e máxima das sub-bacias ( $D v$ média e máxima) apresentam a seguinte estrutura espacial: (i) sub-bacias do extremo sudeste apresentam declividades média e máxima, respectivamente, entre 12-14 e 35-40 graus; (ii) sub-bacias da porção norte, apresentam declividade média entre 10 e 12 graus e máxima entre 35 e 40 graus; (iii) sub-bacias da sinclinal da Moeda apresentam declividade média-baixa entre 8 e 10 graus; (iv) sub-bacias de sudoeste não apresentam estrutura espacial. A porção norte apresenta uma bacia que distingue das outras seis, tendo declividade média entre 12 e 14 graus e máxima acima de 40 graus (Figura 4). Verifica-se, portanto, que os valores de $D v$ máxima e média apresentam agrupamentos fortes.

Os valores calculados para $D d, D h, M f, C m$ e $D v$, apresentam correlação com o quadro geológico, já que os valores calculados variam espacialmente de modo coincidente com as unidades litológicas, conforme pode ser observado no mapa “Compartimentação Litológica” da Figura 4. A influência lito-estrutural sobre as características do relevo e da rede de drenagem é marcante na porção norte da bacia do alto Rio das Velhas, incluindo o Sinclinal Moeda. As sub-bacias que têm mais de 75\% de sua área sobre as rochas do Supergrupo Velhas apresentam organização semelhante para todos os parâmetros calculados. Além disso, as duas sub-bacias do extremo norte, afluentes do Ribeirão Sabará, apresentam valores semelhantes para a maioria dos parâmetros (exceto $R g$ e $I r$ ) e características diferentes das demais sub-bacias da porção norte.A influência lito-estrutural nas bacias da porção sul é de identificação mais difícil, dada a maior heterogeneidade litológica na área, conforme apresentado na Figura 4. Entretanto, as sub-bacias da porção sudoeste correspondem a um agrupamento espacial, facilmente identificado para $R b, R l, R a, I r, D d, D h, C m, M f$ e $D v$. Dessa forma, pode ser concluído que esse agrupamento apresenta características morfométricas semelhantes, também devido a sua composição litológica heterogênea. Fica constatado, portanto, que há uma forte influência lito-estrutural sobre as características morfométricas das sub-bacias do alto Rio das Velhas: os compartimentos morfométricos são formados por sub-bacias que são litologicamente homogêneas ou heterogêneas. Isso significa dizer que, em geral, bacias com proporção de litologias semelhantes apresentam características morfométricas também semelhantes.

Entretanto, essa correspondência entre morfometria e geologia não se aplica às sub-bacias que drenam o embasamento cristalino do Complexo do Bação. As características morfométricas destas sub-bacias apresentam variação espacial em dois agrupamentos principais: sub-bacias de oeste e sub-bacias de leste. Os parâmetros $D d, D h$ e $D v$, calculados para a porção oeste (W) são mais elevados do que os calculados para a leste (E), indicando que a porção oeste é mais bem drenada e tem maior capacidade de infiltração. Além desses parâmetros, o Ir também marca a diferença das características do relevo e da rede de drenagem, dada sua representativa diferença ( $I r$ leste é aproximadamente $50 \%$ maior que em oeste) entre os valores calculados: Ir da porção oeste é igual a 140; e Ir da porção leste igual a 215, conforme indicado na Figura 5. Essa diferença demonstra que a influência lito-estrutural sobre as bacias que drenam o Complexo do Bação é menos marcante do que outros fatores não observáveis por meio dos parâmetros aplicados.
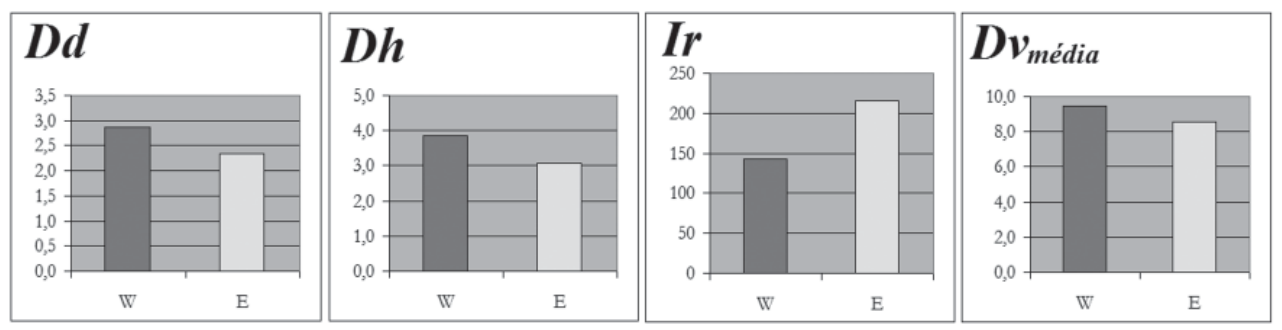

Figura 5 - Comparação dos parâmetros morfométricos dos compartimentos morfométricos oeste (W) e leste (E) que drenam o Complexo do Bação. 
Os dados morfométricos permitem compartimentar a bacia do alto Rio das Velhas em cinco grupos: (i) Norte $(N)-$ afluentes do Ribeirão Sabará; (ii) Meio-Norte $(m N)$ - bacias com mais de $75 \%$ de área nas rochas do Supergrupo Minas; (iii) Oeste $(W)$ - afluentes do Ribeirão do Peixe, que drenam o Sinclinal Moeda (Supergrupo Velhas); (iv) Sudoeste ( $S W$ ) - bacia do Rio Itabirito ou porção com heterogeneidade litoestrutural; e (v) Sudeste (SE) - bacia do alto Rio das Velhas a montante da confluência com o Rio Itabirito, também com heterogeneidade lito-estrutural (Figura 6).

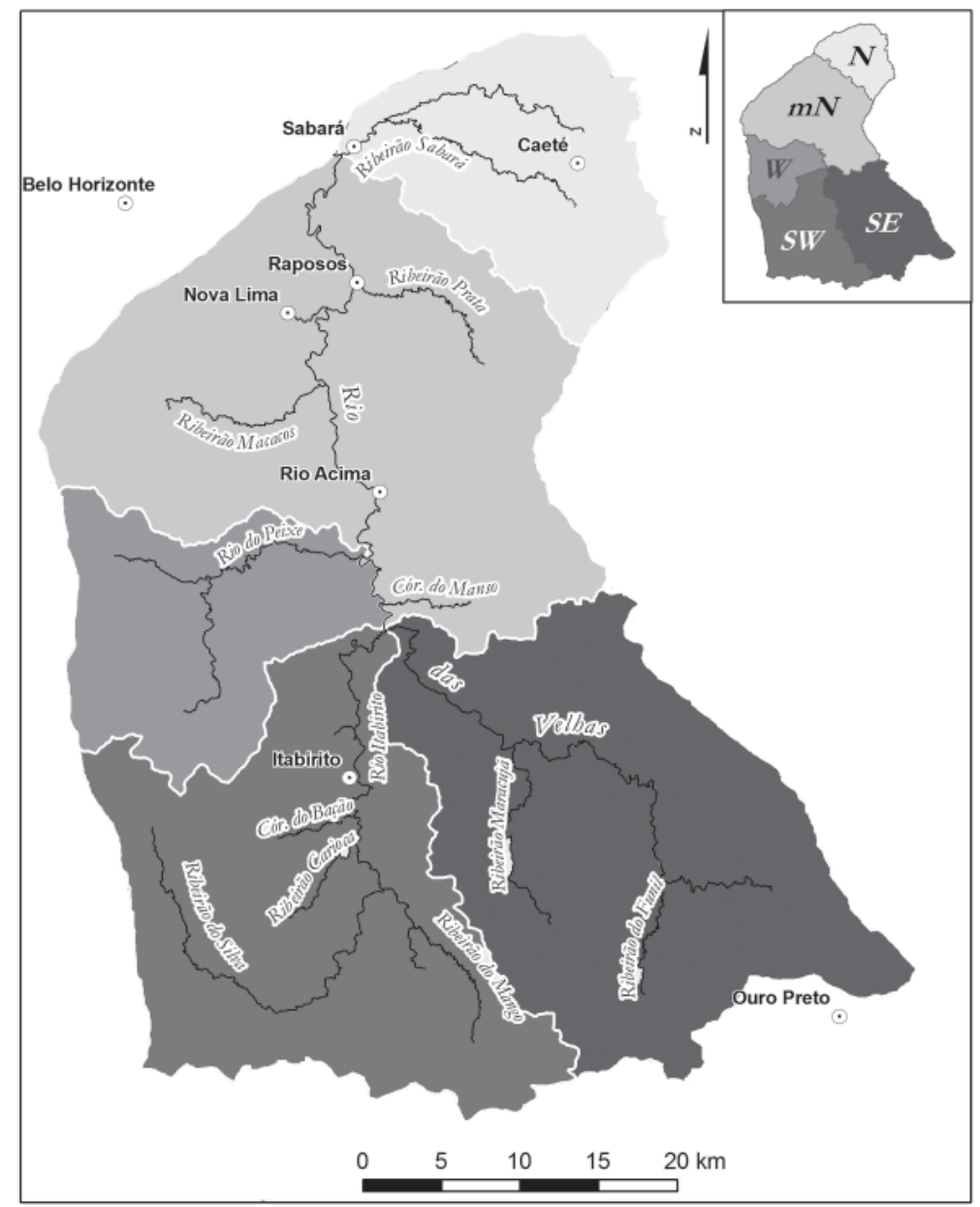

Figura 6 - Compartimentação morfométrica da bacia do alto Rio das Velhas: $\mathbf{N}$-Compartimento Norte; $\boldsymbol{m} \boldsymbol{N}$-Compartimento Meio Norte; $\boldsymbol{W}$-Compartimento Oeste; $\boldsymbol{S} \boldsymbol{W}$-Compartimento Sudoeste; $\boldsymbol{S E}$ - Compartimento Sudeste.

Em geral, a compartimentação morfométrica da bacia segue o arranjo lito-estrutural espacial. Os três compartimentos da porção norte da área de estudo tem suas características marcantemente influenciadas pela geologia, sendo os compartimentos norte e meio-norte quase completamente correspondentes as rochas do Supergrupo Rio das Velhas e o compartimento oeste correspondente as rochas do Supergrupo Minas no interior do sinclinal Moeda. Os compartimentos da porção sul da bacia (sudoeste e sudeste) são também influenciados pela litologia, observados os valores dos índices de rugosidade ( $I r)$, densidade de drenagem $(D d)$ e declividade média $(D v)$, especialmente para as bacias do extremo sudeste que drenam as rochas do Supergrupo Rio das Velhas.
A influência de componentes litológico-estruturais na configuração do relevo é também marcante quando as bacias apresentam os três domínios geológicos, como é o caso dos compartimentos ao sul (Figuras 4 e 6). Em ambos os compartimentos (sudoeste e sudeste), em especial para o sudoeste, as bacias com maior heterogeneidade geológica apresentam um forte agrupamento espacial para os parâmetros morfométricos calculados (Tabela 2).

Os resultados observados nessa análise morfométrica podem auxiliar os estudos sobre o condicionamento tectônico da área quando complementados a evidências empíricas de estudos de geomorfologia estrutural e fluvial. Evidências de eventos neotectônicos vêm sendo levantados no Quadrilátero 
Ferrífero por elementos da geomorfologia fluvial regional que abrangem não apenas o vale do Rio das Velhas (Magalhães Jr. \& Saadi, 1994), mas também de afluentes, como o rio Maracujá (Barros et al., 2008) e o rio do Mango (Raposo et al., 2008).

\section{Considerações Finais}

A bacia do alto Rio das Velhas tem sido objeto de estudo em diversas pesquisas geomorfológicas desde meados do século XX. Entretanto, a configuração do relevo e da rede de drenagem ainda não havia sido espacializada ou quantificada por meio de análise morfométrica dos atributos de suas sub-bacias. Os resultados dessa análise comparativa entre a morfometria das sub-bacias de quinta ordem permitiram a compartimentação da bacia do alto Rio das Velhas em cinco grupos . Essas regiões foram delimitadas de acordo com a estrutura (ou arranjo) espacial dos parâmetros utilizados. Sete dos onze parâmetros utilizados formam agrupamentos bem homogêneos (forte), três parâmetros, agrupamentos pouco homogêneos (fracos) e um último parâmetro constitui um agrupamento heterogêneo (aleatório). O cálculo dos parâmetros para a bacia do alto Rio das Velhas como um todo e para suas sub-bacias de quinta ordem permitiu verificar como a alteração da escala de análise é importante para que os resultados não sejam mascarados por aspectos lito-estruturais.

Os agrupamentos da porção norte da bacia apresentaram forte controle lito-estrutural na configuração do relevo e da rede de drenagem, além de corresponderem às porções mais dissecadas do relevo da bacia. Por outro lado, os dois agrupamentos da porção sul apresentaram marcante diferenciação nos valores dos parâmetros, havendo variações até mesmo dentro de uma unidade lito-estrutural, o Complexo do Bação. A distinção dessa unidade geológica em dois compartimentos (leste e oeste) é mais um indício de presença de atividade neotectônica na bacia do alto Rio das Velhas que condiciona o variação espacial do nível de base local, corroborando os resultados apresentados por Santos et al. (2009). Entretanto, para que o entendimento da dinâmica neotectônica da região seja completo são necessários outros estudos geomorfológicos.

Além de enriquecer a geomorfologia regional do Quadrilátero Ferrífero, esse estudo serve de base para que as linhas gerais traçadas para a gestão territorial e ambiental da bacia do alto Rio das Velhas possam ser complementadas com dados geomorfológicos de caráter espacial.

\section{Agradecimentos}

Os autores agradecem a Fundação de Amparo à Pesquisa de Minas Gerais (FAPEMIG) pelo apoio financeiro por meio de bolsa de mestrado, no Programa de Pós-Graduação em Análise e Modelagem de Sistemas Ambientais da UFMG, e ao Grupo de Pesquisa Geomorfologia e Recursos Hídricos (Laboratório de Geomorfologia, Instituto de Geociências, UFMG).

\section{Referências Bibliográficas}

ALKMIM F. F.; MARSHAK S. Transamazonian orogeny in the Southern São Francisco Cráton Region, Minas Gerais, Brazil: Paleoproterozoic collision and collapse in the Quadilátero Ferrífero. Precambrian Research, v. 90, p. 29-98, 1998.

BARBOSA G. V. Superfícies de erosão no Quadrilátero Ferrífero. Revista Brasileira de Geociências, v.10, n.1, p.89-101, 1980.

BARBOSA G. V.; RODRIGUES D. M. S. Quadrilátero Ferrifero. Belo Horizonte, IGC/UFMG. 130p., 1967.

BARROS, L. F. P.; RAPOSO, A. A.; MAGALHÃES Jr, A. P.; CHEREM, L. F. S. Níveis e seqüências deposicionais fluviais cenozóicos no vale do Rio Maracujá, Quadrilátero Ferrífero, MG Ouro Preto/MG. In: SIMPÓSIO NACIONAL DE GEOMORFOLOGIA, 7, 2008. Belo Horizonte. Anais.... Belo Horizonte : Tec Art. 2008. p.140-150.

CHRISTOFOLETTI, A. Modelagem de sistemas ambientais. São Paulo: Edgard Blücher, 1999. 186p.

FELTRAN FILHO, A.; LIMA, E. F. Considerações morfométricas da bacia do rio Uberabinha - Minas Gerais. Sociedade e Natureza. Uberlândia:UFU, v.19. n.1, p.65-80, 2007.

FIGUEIREDO, M.A., VARAJÃO, A.F.F.C., FABRIS, J.D. and LOUTFI, I.S. Alteração superficial e pedogeomorfologia no sul do Complexo Bação - Quadrilátero Ferrifero (MG). Revista Brasileira de Ciências do Solo, v.28, p.713-729, 2004.

HORTON, R. E. Erosional development of streams and their drainage basins: hydrographical approach to quantitative morphology. Geological Society of America Bulletin, v.56, n.2, p.275-370, 1945.

JENKS, G. The data model concept in statistical mapping. International Yearbook of Cartography, v.7, p.186-190, 1967

MAGALHÃES JR, A.P.; SAADI, A. Ritmos da dinâmica fluvial neo-cenozóica controlados por soerguimento regional e falhamento: o vale do Rio das Velhas na Região de Belo Horizonte, Minas Gerais, Brasil. Geonomos, v.2, n.1, p.42-54, 1994.

RAPOSO, A.A.; OLIVEIRA, L.F.; MAGALHÃES Jr, A.P.; CHEREM, L.F.S. Níveis e sequiências deposicionais do vale do Ribeirão do Mango - Quadrilátero Ferrífero/MG. In: Simpósio Nacional de Geomorfologia, 7, 2008, Belo Horizonte. Anais... Belo Horizonte : Tec Art. v.1., 2008, p.110-120. 
RUSZKICZAY-RUDIGER, Z. Tectonic and climatic forcing in Quaternary landscape evolution in the central Pannonian Basin: A quantitative geomorphological geochronological and structural analysis. Tese de Doutorado, Vrije University, Amsterdã, 2007. 149p. Disponível em: <http://hdl.handle. net/1871 /10689> Acessado em: 20 de março de 2008.

SALGADO, A.A.R.; BRAUCHER, R.; VARAJÃO, C.A.C.; COLIN, F.; VARAJÃO, A.F.D.C.; NALINI JR, H.A. Relief evolution of the Quadrilátero Ferrífero (Minas Gerais, Brazil) by means of (10Be) cosmogenic nuclei. Zeitschrift für Geomorphologie, v.52, n.3, p.317-323, 2008.

SANTOS, C. A.; SOBREIRA, F. G. Análise morfométrica como subsídio ao zoneamento territorial: o caso das bacias do Córrego Carioca, Córrego do Bação e Ribeirão Carioca na região do Alto Rio das Velhas-MG. Revista da Escola de Minas, v.61, n.1, p.77-85, 2008.

SANTOS, G.B.; MAGALHÃES JR, A.P.; CHEREM, L.F.S. Eventos paleodeposicionais e a dinâmica fluvial recente do alto vale do Rio das Velhas, Quadrilátero Ferrífero, MG. Revista Brasileira de Geomorfologia, v.10, n.2, p.74-89, 2009.

SAUCHYN, D.J.; CRUDEN, D.M.; HU, X.Q. Structural control of the morphometry of open rock basins, Kananski region, Canadian Rocky Mountains. Geomorphology, v.22 p.313-324, 1998.
SCHEIDEGGER, A.E. Morphometric analysis and its relation to tectonics in Macaronesia. Geomorphology, v.46, p.96-115, 2002.

SCHUMM, S.A. Evolution of drainage systems and slopes in badlands at Perth Amboy. Geological Society of America Bulletin, v.67, p.597-646, 1956.

STRAHLER, A.N. Hypsometric (area-altitude) - analysis of erosion al topography. Geological Society of America Bulletin, v.63, n.10 p.1117-1142, 1952.

VARAJÃO, C.A.C. ; SALGADO, A.A.R.; BRAUCHER, R.; COLIN, F.; VARAJÃO, A.F.D.C.; NALINI JR, H.A. Estudo da paisagem do Quadrilátero Ferrífero (Minas Gerais, Brasil) por meio da mensuração das taxas de erosão (10Be) e da pedogênese. Revista Brasileira de Ciências do Solo, v.33, p.1409-1425, 2009

VESTENA, L.R.; CHECCHIA, T.; KOBIYAMA, M. Análise morfométrica da bacia hidrográfica do Caeté, Alfredo Wagner/ SC. In: Simpósio Nacional de Geomorfologia, 6. 2006. Goiânia. Anais... Goiânia:UFGO, 2006, 8 p.

WALCOTT, R.C.; SUMMERFIELD, M.A. Scale dependence of hypsometric integrals: an analysis of southeast African basins. Geomorphology, v.96, n.1, p.174-186, 2007. 